\title{
Quality of Life in Ovarian-Cancer Patients Receiving Chemotherapy
}

\author{
Tohmina Akhter ${ }^{1}$, Shahana Pervin'1, Annekathryn Goodman ${ }^{2 *}$ \\ ${ }^{1}$ Department of Gynaecologic Oncology, National Institute Cancer Research and Hospital, Dhaka, Bangladesh \\ ${ }^{2}$ Division of Gynecologic Oncology, Massachusetts General Hospital, Boston, MA, USA \\ Email: tohminakgh@gmail.com, shahana.pervin@yahoo.com, *agoodman@mgh.harvard.edu
}

How to cite this paper: Akhter, T., Pervin, S. and Goodman, A. (2020) Quality of Life in Ovarian-Cancer Patients Receiving Chemotherapy. Journal of Cancer Therapy, 11, 695-714.

https://doi.org/10.4236/jct.2020.1111059

Received: October 25, 2020

Accepted: November 16, 2020

Published: November 19, 2020

Copyright (c) 2020 by author(s) and Scientific Research Publishing Inc. This work is licensed under the Creative Commons Attribution International License (CC BY 4.0).

http://creativecommons.org/licenses/by/4.0/

(c) (i) Open Access

\begin{abstract}
Background: Ovarian cancer accounts for $4 \%$ of cancers occurring in women and ranks first in gynecological cancer mortality. Maintaining and improving quality of life is an important goal of cancer treatment. The toxicities of cancer treatment particularly chemotherapy can impact an individual's wellbeing. Objective: Assessment of quality of life among ovarian cancer patients receiving chemotherapy. Method: A descriptive study was conducted among 202 patients with ovarian cancer treated at the National Institute of Cancer Research and Hospital in Bangladesh. Ethical approval was received from the ethics committee of NICRH. Data was collected using the EORTC QLQC30 questionnaire and the ovarian cancer specific EORTC QOL OV-28 module. Functional, symptomatic and global variables were scored and analyzed by SPSS. Multiple linear regressions determined the effects of predictor variables and correlation of the global health status with other variables. Results: $48.6 \%$ of patients were ages 41 to 50 years. The mean score of global health status was 55.77. Deteriorating emotional function, distressing physical and psychological symptoms, sexual dysfunction and financial difficulties adversely affect the quality of life. Their correlation with global health status was strongly significant $(\mathrm{P}$ value $<0.05)$. Fatigue $(\mathrm{r}$ value $-0.604 ; \mathrm{p}<0.05)$ loss of appetite $(\mathrm{r}$ value $-0.442 ; \mathrm{p}<0.05$ ), insomnia ( $\mathrm{r}$ value $-0.339 ; \mathrm{p}<0.05$ ), dyspnea ( $\mathrm{r}$ value $-0.377 ; \mathrm{p}<0.05$ ), heartburn ( $\mathrm{r}$ value $-0.369 ; \mathrm{p}<0.05$ ), and alopecia ( $\mathrm{r}$ value $-0.262 ; \mathrm{p}<0.05)$ were negatively associated with QOL. Conclusion: The overall quality of life among the ovarian cancer patients receiving chemotherapy is low. Increasing knowledge in this area will help clinicians to optimize patient management. Interventions should focus on both physical and psychological and sexual health issues that adversely affect the quality of life.
\end{abstract}

\section{Keywords}

Quality of Life, EORTC QLQ C30, EORTC QOL OV-28, Ovarian Cancer, 
Chemotherapy, Bangladesh

\section{Introduction}

Ovarian cancer ranks third in gynecological malignancies and accounts for $4 \%$ of female malignancies [1] [2]. With over $70 \%$ of women diagnosed with advanced disease (stages III and IV), it has the worst prognosis and the highest mortality rate of all gynecologic malignancies [3] [4]. In the United States, an estimated 21,750 new cases of ovarian cancer will be diagnosed and 13,940 women will die of ovarian cancer in 2020 with a $46.2 \%$ five-year survival [5]. While surgery and chemotherapy are the cornerstones of therapy for advanced ovarian cancer, standard combination platinum-based chemotherapy can adversely affect an individual's wellbeing. The term quality of life (QoL) is used to evaluate the general well being of individuals and societies. According to the World Health Organization (WHO), quality of life (QoL) is defined as an individual's perception of life, values, objectives, standards, and interests in the framework of culture [6]. Illness-related factors and distress symptoms in cancer patients are due to detrimental effects of chemotherapy negatively impact QoL. QoL has been used as a primary outcome measure in studies to evaluate the effectiveness of treatment [7] [8] [9]. In the past five years, documentation of patient-reported outcomes has become an important metric associated with both quality of life and overall survival [10] [11]. Health-related quality of life is an important goal of cancer treatment and is a multi-dimensional concept that includes domains related to physical, mental, emotional, and social functioning. Standard chemotherapy regimens for ovarian cancer cause both short-term and long-term toxicities [12]. Chemotherapy-induced functional, psychological impairment and sexual dysfunction during treatment can have a great impact on the health-related quality of life. While quality of life is important to evaluate in cancer care, there are few studies from low-income countries where there is a rising incidence of gynecological cancers [13] [14]. Assessment of quality of life and identification of risk factors associated with poor health-related quality of life could aid in planning interventions to potentially improve outcomes.

\section{Methods}

A cross-sectional, observational study analyzed Quality of Life (QoL) factors for 202 patients who received chemotherapy for ovarian cancer from January 2019 to December 2019 at the National Institute of Cancer Research and Hospital (NICRH) in Dhaka, Bangladesh. The inclusion criteria were ovarian cancer patients who were receiving chemotherapy. Terminally ill patients and patients with dual malignancy were excluded from this study. Ethical approval was obtained from the ethics committee of NICRH. A convenience sampling method was used in this study [15]. All participants signed a written consent, were in- 
formed of the purpose of the study and voluntarily chose to participate by completing an anonymous structured validated Bangla version of the EORTC QLQ C30 questionnaire and ovarian cancer specific EORTC QOL OV-28 questionnaire [16]. Three scales, a functional scale, a symptomatic/single item scale, and a global health status scale, were used for the assessment of quality of life. The functional scale included questions on the following functioning domains: physical, role, emotional, cognitive, and social. The symptom scales/items for the ovarian cancer module QLQ-OV28 included the following: abdominal/GI, peripheral neuropathy, hormonal, body image, attitude to disease/treatment, chemotherapy side effects, other single items and sexuality. The EORTC scoring manual was used to calculate scores [17]. Each of the multi-item scales included a different set of items. Symptom and single item scale were scored as the grade of severity of symptoms or interference of the treatment in patients' family life, social life, financial status and sexual life etc. The symptomatic and single item score values of $0,1,2,3$ (Not at all symptomatic to very much symptomatic) were assigned for each item. Global health status scale scores were calculated from the scores of overall health status and overall quality of life. These subscales scores were assigned as $0,1,2,3,4,5,6$ (Very poor to excellent).

At first the average of the items were estimated and called raw scores. A linear transformation was used to standardize each raw score. The final scores ranged from 0 - 100. The following formulas were used for linear transformation for calculating the scores that will ultimately reflect the patient's quality of life.

$$
\begin{aligned}
& \text { Functional scales: } S=(1-[\text { Row score }-1] / \text { range }) \times 100 \\
& \text { Symptom scale/items: } S=([\text { Row score }-1] / \text { range }) \times 100 \\
& \text { Global health status/QOL: } S=([\text { Row score }-1] / \text { range }) \times 100
\end{aligned}
$$

A high score for functional scale represents a high and health level of functioning. A high score for global health status indicates high QoL. A high score for a symptom scale represents a high level of symptoms and physical problems. A low score for a symptom scale/single item represents low level of symptomatology/problems and thus improve QoL. The global health status scale depends upon functional and symptomatic scale/single items.

The participants' demographics including comorbidities, age, and socioeconomic, educational, and marital status were recorded. Pew Research Center Analysis was used to define income levels [18]. Low income is defined as earning less than or equal to 4920 Bangladesh taka (TK) (\$58 USD) per month. Low-middle income is a monthly income ranging from 4920 TK to 24,600 TK (\$290 USD). The middle-income group included those earning 24,600 TK to 49,200 TK ( $\$ 580$ USD) per month. According to the PEW report, upper middle-income levels are between 49,200TK and 1,230,000 TK ( $\$ 1450$ USD) per month, and high-income levels are greater than 1,230,000 TK per month in Bangladesh. There were no participants at NICRH in the upper-middle income and high-income socio-economic categories. The costs of therapy were obtained from the adminis- 
trative office at NICRH.

From the participants' chart review, clinic-pathologic features of the ovarian cancers including histopathologic subtype, grade, and stage were recorded. Also documented was the type of chemotherapy, number of cycles received, and at which cycle of chemotherapy the Bangla version of the EORTC QLQ C30 questionnaire and ovarian cancer specific EORTC QOL OV-28 questionnaire was administered. Each participant answered the questionnaires once.

After cleaning and checking the accuracy of the data, the collected data were coded, transferred and analyzed by using SPSS (version 18).

\section{Results}

The characteristics of the 202 ovarian cancer patients who attended NICRH and received chemotherapy during the study period are summarized in Table 1 . The mean age of the cohort was 48 years old. Forty eight percent was in the 41 to 50 year age group (Figure 1). Almost fifty-nine percent were from the low-income group. Close to forty-two percent of the participants were illiterate and 50.5\% had completed their primary education. Ninety-four percent were married. Regarding comorbidities such as hypertension, cardiac disease, diabetes, thyroid disease, and pulmonary diseases; $26 \%$ experienced one of the comorbidities and $11 \%$ were suffering from two or more comorbidities.

The financial burden for these patients was significant. At NICRH, a government funded institution, almost all chemotherapy drugs and anti-emetics are supplied free of charge. However, patients must pay for intravenous fluids, blood transfusions, and laboratory testing. Ninety-eight percent of participants in this study received chemotherapy in the outpatient setting where there was no bed cost. For patients who are admitted, there are free beds for the very poor, a paying bed in a ward costs 283 Taka (\$3 USD) daily and a private room costs 432 Taka ( $\$ 5$ USD) daily at NICRH. Table 2 summarizes the costs of therapy for this predominantly lower income population in Bangladesh.

Table 1. Characteristics of 202 participants with ovarian cancer receiving chemotherapy at NICRH.

\begin{tabular}{|c|c|c|c|c|}
\hline Characteristics & N (\%) & N (\%) & N (\%) & N (\%) \\
\hline \multirow{4}{*}{ Socioeconomic status ${ }^{\mathrm{a}}$} & Lower Income & Lower-middle & Middle Income & \\
\hline & (Earning $\$ 58$ & (Earning $\$ 58-\$ 290$ & (Earning $\$ 290-\$ 580$ & \\
\hline & USD/month) & USD/month) & USD/month) & \\
\hline & $110(54 \%)$ & $48(24 \%)$ & $44(22 \%)$ & \\
\hline \multirow[t]{2}{*}{ Education } & None & Primary School & Secondary School & Higher Education \\
\hline & $84(41.6 \%)$ & $102(50.5 \%)$ & $12(5.9 \%)$ & $4(2 \%)$ \\
\hline \multirow[t]{2}{*}{ Marital status } & Single & Married & & \\
\hline & $14(6.9 \%)$ & $188(93.1 \%)$ & & \\
\hline \multirow[t]{2}{*}{ Comorbidities $^{\mathrm{b}}$} & None & One & Two or more & \\
\hline & $128(63.4 \%)$ & $52(25.7 \%)$ & $22(10.9 \%)$ & \\
\hline
\end{tabular}

${ }^{a}$ Pew research center analysis; ${ }^{\mathrm{b} H y p e r t e n s i o n, ~ c a r d i a c ~ d i s e a s e, ~ d i a b e t e s, ~ t h y r o i d ~ d i s e a s e, ~ o r ~ p u l m o n a r y ~ d i s e a s e s . ~}$ 


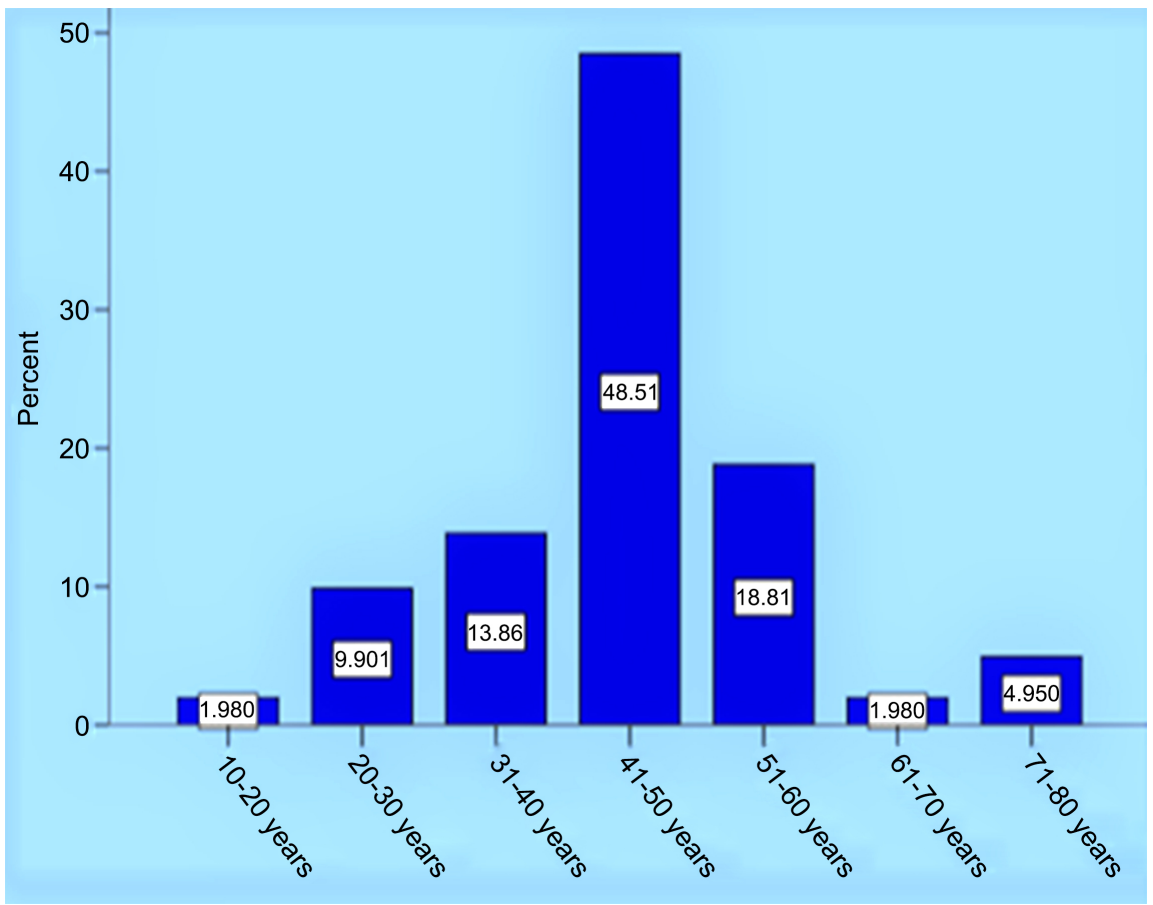

Figure 1. Age distribution of 202 participants with ovarian cancer receiving chemotherapy at NICRH.

Table 2. Costs of cancer therapy at national institute cancer research hospital and in Bangladesh.

\begin{tabular}{|c|c|c|c|c|}
\hline Medical Care & $\begin{array}{c}\text { Costs } \\
\text { (US Dollar) }\end{array}$ & $\begin{array}{c}\text { Costs } \\
\text { (US Dollar) }\end{array}$ & $\begin{array}{c}\text { Costs } \\
\text { (US Dollar) }\end{array}$ & $\begin{array}{l}\text { Costs } \\
\text { (USD) }\end{array}$ \\
\hline \multirow[t]{2}{*}{ Type of Bed } & Outpatient $^{a}$ & Inpatient Ward & $\begin{array}{c}\text { Inpatient Private } \\
\text { Room }\end{array}$ & \\
\hline & No Charge & $\$ 3$ per day & $\$ 5$ per day & \\
\hline \multirow[t]{2}{*}{ Chemotherapy $^{\mathrm{b}}$} & Paclitaxel & Carboplatin & Cisplatin & Gemcitabine \\
\hline & $\$ 112$ Per dose & $\$ 38$ Per dose & $\$ 11$ Per dose & $\$ 48$ Per dose \\
\hline \multirow[t]{2}{*}{ Supportive Care } & Growth Factor & Intravenous Fluid & Saline Set & \\
\hline & $\$ 24$ Per dose & $\$ 4$ & $\$ 3$ & \\
\hline \multirow[t]{2}{*}{$\begin{array}{c}\text { Blood } \\
\text { Transfusions }\end{array}$} & Transfusion Set & $\begin{array}{l}\text { Screen And Cross } \\
\text { Match Blood }\end{array}$ & $\begin{array}{l}\text { Buy Blood From } \\
\text { Blood Bank }\end{array}$ & \\
\hline & $\$ 2.5$ & $\$ 5$ & $\$ 59$ & \\
\hline Labs & $\$ 7-\$ 8$ & & & \\
\hline \multirow[t]{2}{*}{ Physician Fee } & NICRH & Private Sector & & \\
\hline & No Charge & $\$ 9-\$ 15$ per visit & & \\
\hline
\end{tabular}

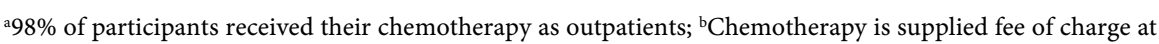
NICRH. 
Tumor characteristics are summarized in Table 3. Epithelial ovarian cancers were the most common subtype of malignancy in 176 (87\%) of participants. The majority of women presented with advanced disease with $55.4 \%$ at Stage III and $30.7 \%$ at Stage IV respectively.

Cytoreductive surgery was performed on 178 (88\%) of patients while 24 patients were only treated with chemotherapy. All participants were treated with combination platinum-based chemotherapy. Table 4 summarizes the range of chemotherapy schedules and number of cycles that participants received at the time of this study. Eighty-four patients (42\%) received four to six cycles and fifty-eight patients $(29 \%)$ received seven to twelve cycles of chemotherapy. The majority $(84 \%)$ was treated with carboplatin and paclitaxel.

Table 5, Table 6 and Table 7 itemize the scores from the Bangla version of the EORTC QLQ C30 questionnaire and ovarian cancer specific EORTC QOL OV-28 questionnaires given to the 202 participants. Regarding the functional scales, the physical function score average was $56.7 \pm 27.7$, but the emotional function scores were lower at an average of $50.17 \pm 24.5$. Cognitive function score was $77.2 \pm 25.9$.

Table 3. Histopathology for 202 participants with ovarian cancer receiving chemotherapy at NICRH.

\begin{tabular}{|c|c|c|c|c|}
\hline Characteristics & $\mathrm{N}(\%)$ & $\mathrm{N}(\%)$ & $\mathrm{N}(\%)$ & $\mathrm{N}(\%)$ \\
\hline \multirow[t]{2}{*}{ Stage } & I & II & III & IV \\
\hline & $8(4 \%)$ & $20(9.9 \%)$ & $112(55.4 \%)$ & $62(30.7 \%)$ \\
\hline \multirow[t]{3}{*}{$\begin{array}{c}\text { Epithelial } \\
\text { Ovarian Cancer }\end{array}$} & Serous & Mucinous & Endometrioid & Grade \\
\hline & & & & Grade 2: $64(32 \%)$ \\
\hline & $156(77.2 \%)$ & $12(5.9 \%)$ & $8(4 \%)$ & $\begin{array}{c}\text { Grade 3: } 102(51 \%) \\
\text { Unknown: } 10 \\
(17 \%)\end{array}$ \\
\hline \multirow[t]{2}{*}{ Other Cell Types } & Dysgerminoma & Granulosa Cell & $\begin{array}{l}\text { Metastatic } \\
\text { Krukenberg }\end{array}$ & \\
\hline & $6(3 \%)$ & $14(7 \%)$ & $7(3 \%)$ & \\
\hline
\end{tabular}

Table 4. Chemotherapy regimens for 202 participants with ovarian cancer at NICRH.

\begin{tabular}{ccccc}
\hline & Patients (\%) & Patients (\%) & Patients (\%) & Patients (\%) \\
\hline $\begin{array}{c}\text { Chemotherapy } \\
\text { Regimen }\end{array}$ & $\begin{array}{c}\text { Carboplatin } \\
\text { Paclitaxel }\end{array}$ & $\begin{array}{c}\text { Cisplatin } \\
\text { Paclitaxel }\end{array}$ & $\begin{array}{c}\text { Carboplatin } \\
\text { Gemcitabine }\end{array}$ & $\begin{array}{c}\text { Bleomycin } \\
\text { Etoposide } \\
\text { Cisplatin }\end{array}$ \\
$\begin{array}{c}\text { Number of Cycles } \\
\text { Received }\end{array}$ & $170(84 \%)$ & $8(4 \%)$ & $16(8 \%)$ & $8(4 \%)$ \\
& $46(23 \%)$ & $84(41 \%)$ & $58(29 \%)$ & $14(7 \%)$
\end{tabular}

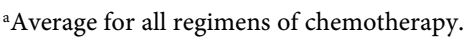


Table 5. EORTC QLC functional scale average for 202 participants with ovarian cancer receiving chemotherapy at NICRH.

\begin{tabular}{ccc}
\hline Functional Scale & Mean & Standard Deviation \\
\hline Physical Function & 56.7 & 27.7 \\
Role Function & 53.7 & 28.1 \\
Cognitive Function & 77.2 & 25.9 \\
Social Function & 44.8 & 18.7 \\
Emotional Function & 50.2 & 24.5 \\
\hline
\end{tabular}

Table 6. EORTC QLC symptom scale average for 202 participants with ovarian cancer receiving chemotherapy at NICRH.

\begin{tabular}{ccc}
\hline Symptom Scale & Mean & Standard Deviation \\
\hline Gastrointestinal & 26.7 & 16 \\
Peripheral neuropathy & 40 & 30 \\
Body Image & 42 & 30.6 \\
Attitude Towards Disease & 46.5 & 27 \\
Side Effects of Chemotherapy & 30 & 20.7 \\
Hormonal Change & 35.5 & 33.2 \\
Fatigue & 47 & 23.7 \\
Nausea/Vomiting & 40.9 & 28.5
\end{tabular}

Table 7. EORTC QLC symptom scale average for 202 participants with ovarian cancer receiving chemotherapy at NICRH.

\begin{tabular}{ccc}
\hline Single Item Scale & Mean & Standard Deviation \\
\hline Hair Loss & 91.4 & 22.4 \\
Upset due to Hair Loss & 52.8 & 26 \\
Financial Difficulties & 49.5 & 31.8 \\
Heartburn & 40.9 & 39.1 \\
Lack of Appetite & 39.6 & 30 \\
Sleep Disturbance & 34 & 35.3 \\
Taste Change & 29.4 & 35 \\
Pain & 26.7 & 32.3 \\
Constipation & 24.4 & 37 \\
Diarrhea & 16.5 & 30 \\
Dyspnea & 10 & 20.8 \\
\hline
\end{tabular}


Symptomatic scales identified a wide variety of symptoms for the study population who were receiving chemotherapy. Fatigue was the most prevalent symptoms. Fatigue, attitude to the disease, nausea, vomiting and body image all affect the quality of life (Figure 2). Psychological issues included anxiety, worry, tension and irritability (Figure 3). Figure 4 illustrates the range of severity for symptoms. For instance, alopecia scores were the highest with $90 \%$ of the study population complaining of significant alopecia. Figure 5 displays the mean of single item scores. Financial difficulties scores averaged at 49 . The entire single item list revealed how these experiences adversely impacted quality of life for the participants.

The mean Global health status was $55.7 \pm 15$. Fifty percent of score ranged between 34 and 66 .

Figure 6 displays the breakdown in Global health status.

Sexual health was very important for improved quality of life. There was one non-responder regarding sexual issues and $49 \%$ of the study group was not sexually active at all (Table 8 ). Of the $51 \%$ who were sexually active, $70 \%$ did not enjoy the sexual activity nor were interested in sex. Sixty percent of patients complained of vaginal dryness. Sexual problems caused stress and a reduction in relationship satisfaction and correlated with higher levels of depression. Figure 7 highlights the range of sexual experience of the participants.

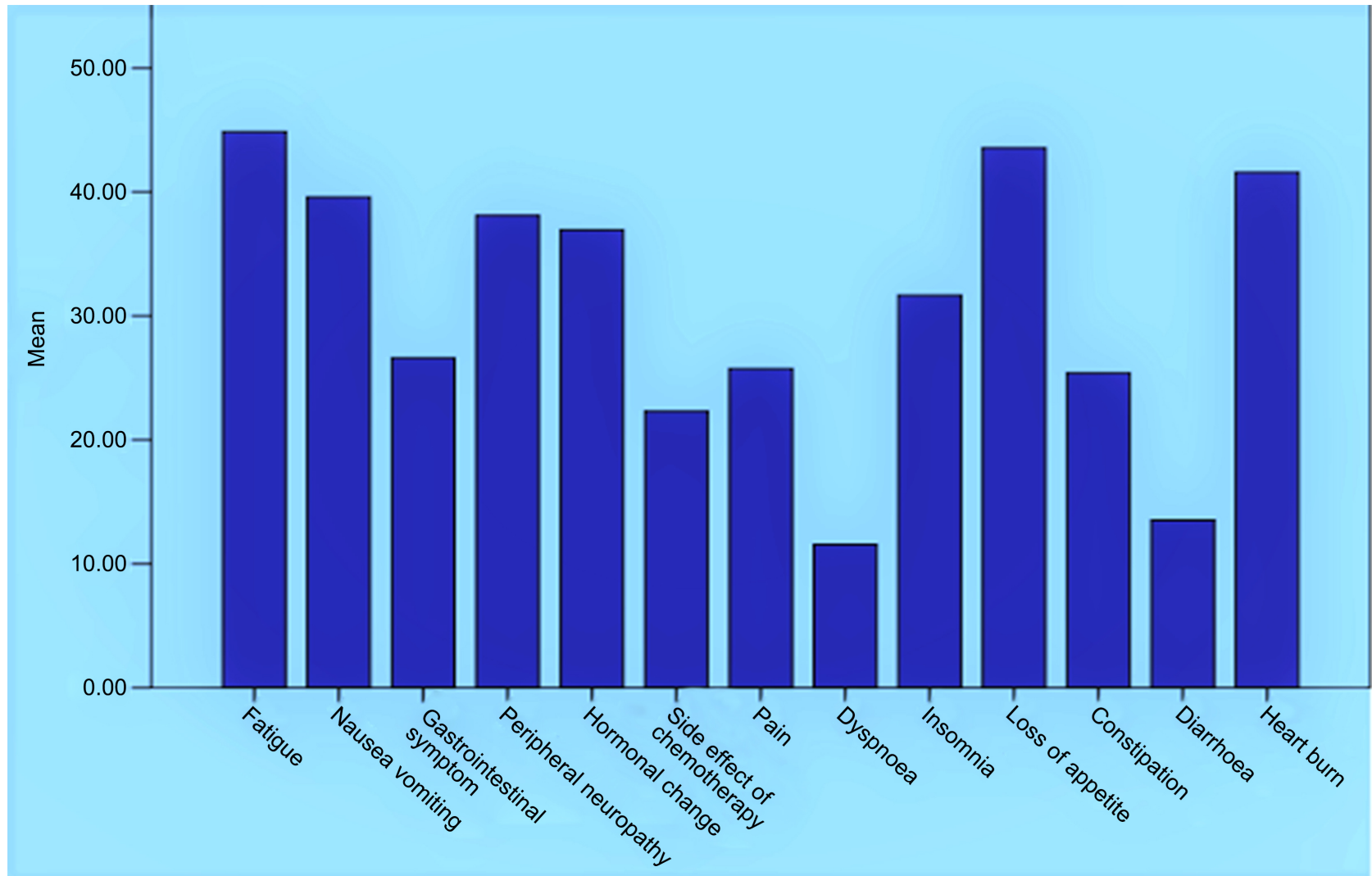

Figure 2. Mean score of the symptom and single item domain scales of EORTC QLC for 202 participants with ovarian cancer receiving chemotherapy at NICRH. 


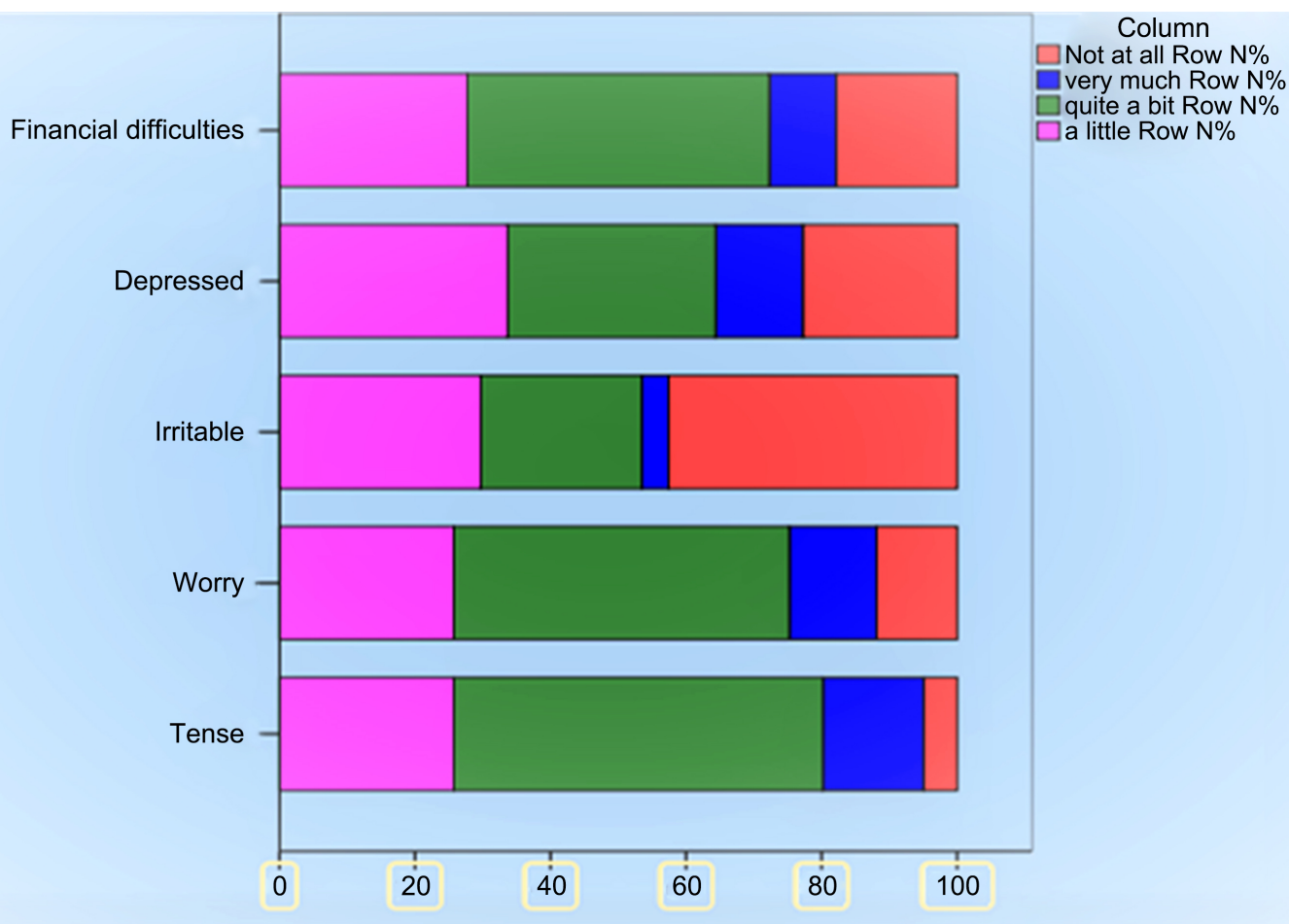

Figure 3. Intensity range of psychological stress reported on EORTC QLC scale for 202 participants with ovarian cancer receiving chemotherapy at NICRH.

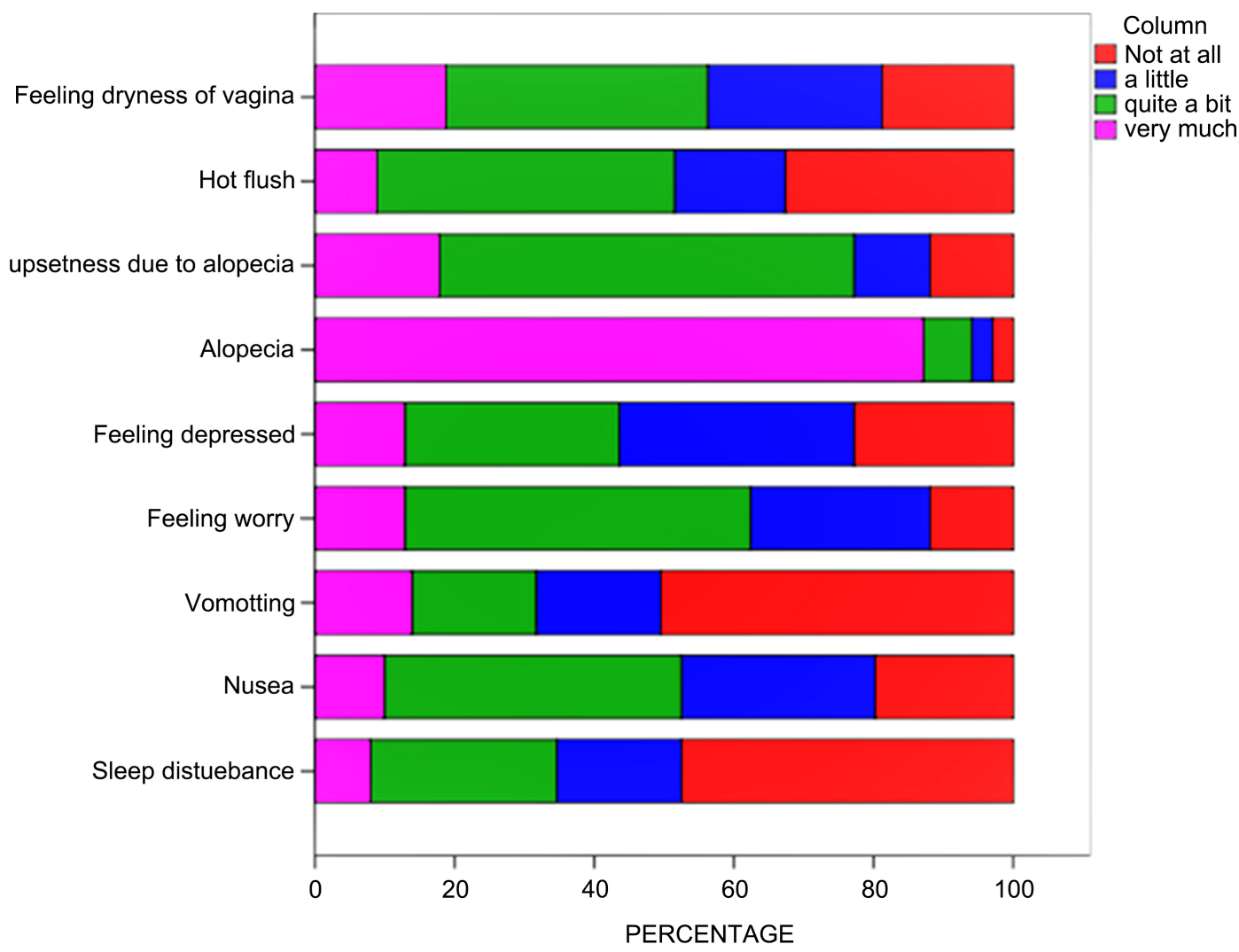

Figure 4. Severity of symptoms reported on EORTC QLC scale for 202 participants with ovarian cancer receiving chemotherapy at NICRH. 


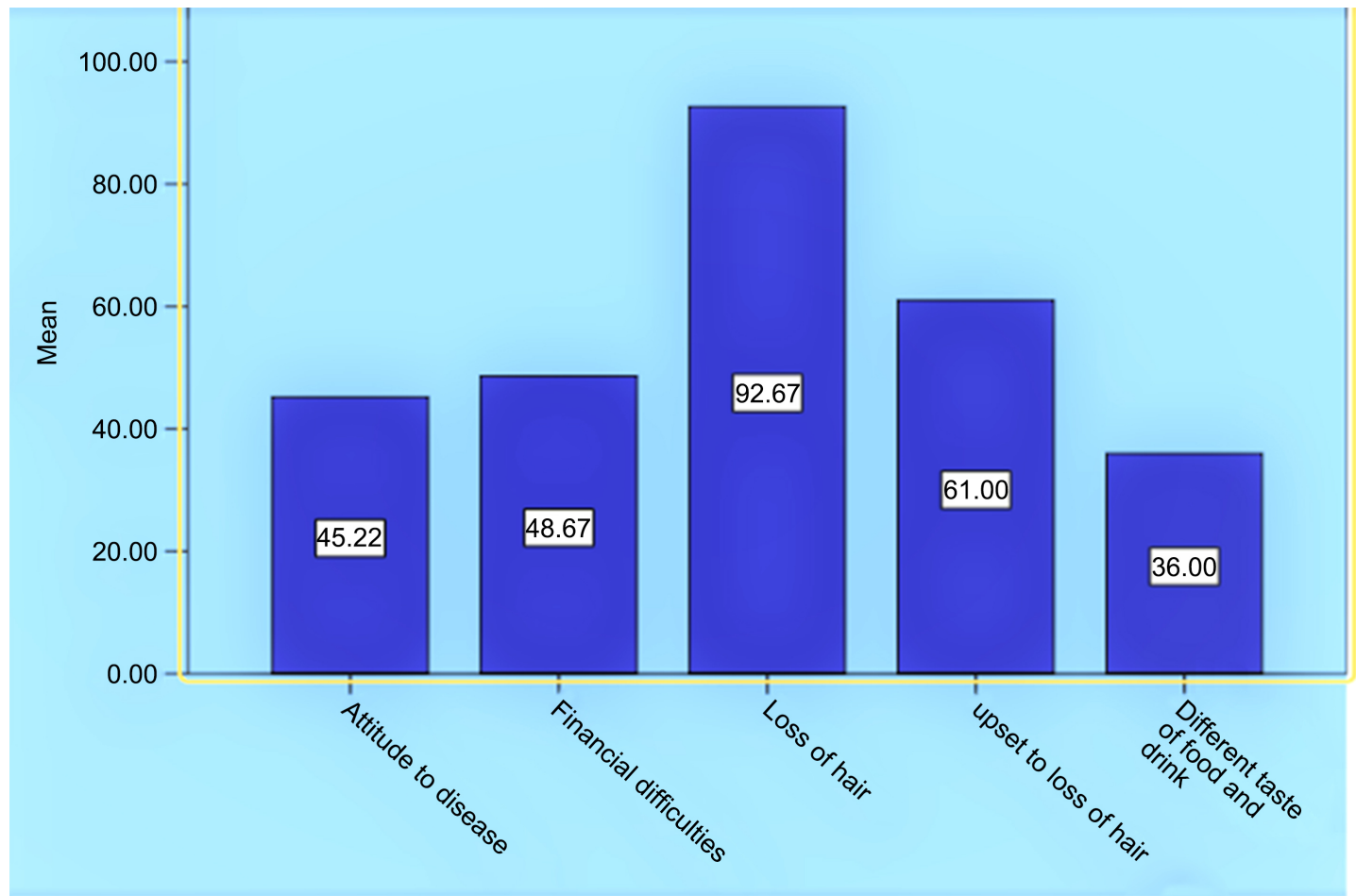

Figure 5. Single item domain scores reported on EORTC QLC scale for 202 participants with ovarian cancer receiving chemotherapy at NICRH.

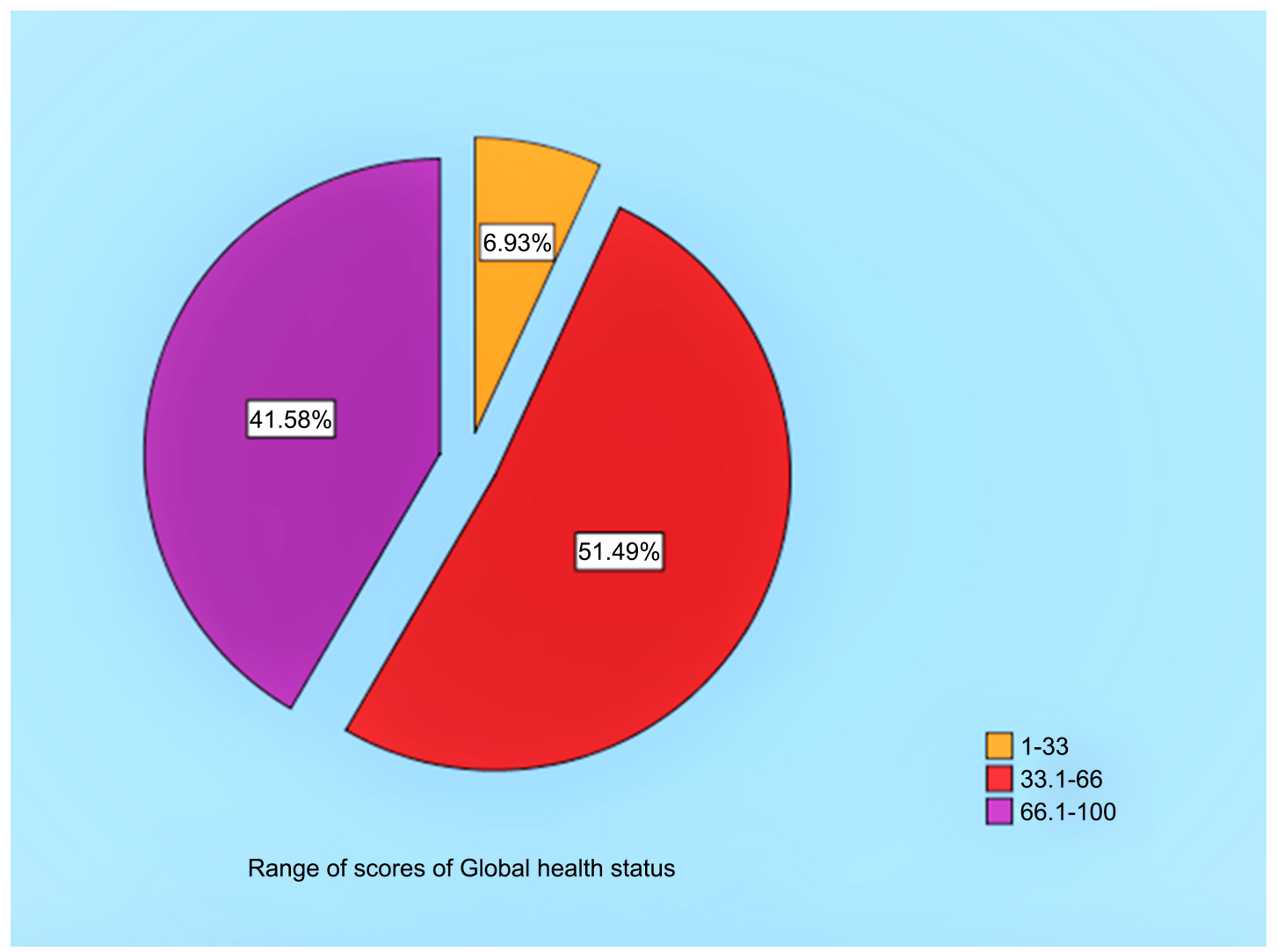

Figure 6. Range of scores of global health status from EORTC QLC scale for 202 participants with ovarian cancer receiving chemotherapy at NICRH. 


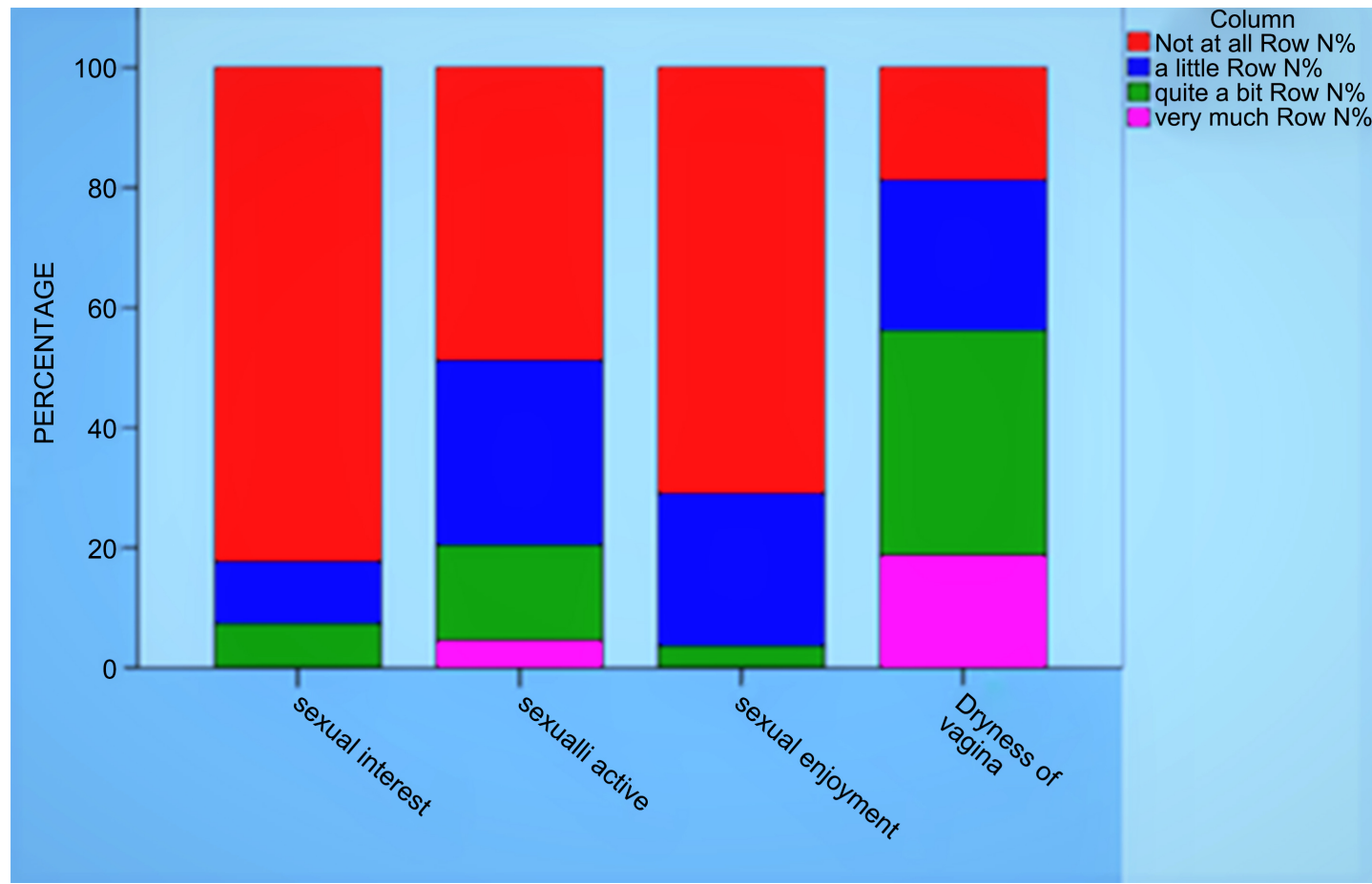

Figure 7. Range of sexual experience for 103 sexually active respondents.

Table 8. Factors affecting sexual health for 103 sexually active participants.

\begin{tabular}{cc}
\hline Sexual Health Related Subscale (EORTC QLC) & Frequency (\%) \\
\hline Sexual Interest (not at all) & $39(38 \%)$ \\
Sexual Enjoyment (not at all) & $56(55 \%)$ \\
Dryness of Vagina & $25(24.5 \%)$ \\
\hline
\end{tabular}

Table 9 displays the multivariate regression analysis. There is a correlation of global health status with functional and symptom scales. Functional domains show moderate strength of positive correlation and it was statistically significant $(p<0.05)$. Fatigue, pain, upset due to loss of hair shows moderate strength of negative correlation with Global health status probability of strength was statistically significant $(\mathrm{p}<0.05)$.

\section{Discussion}

Quality of life is an important issue for maintaining the physical as well as mental health of the cancer patient. Treatment of cancer is associated with high levels of distress and varying degrees of anxiety, depression, powerlessness, sadness, and fear depending on treatment [19]. In another cross-sectional study from Iran, QoL metrics were related to cancer type, pain, and fatigue and were significantly worse for patients during their third to fifth cycle of chemotherapy compared to the first two cycles of chemotherapy [20]. During treatment every effort should be made to identify the factors that will adversely affect the quality of life 
Table 9. Multivariate regression analysis of scores from functional and symptom scores from EORTC QLC scale for 202 participants with ovarian cancer receiving chemotherapy at NICRH.

\begin{tabular}{ccc}
\hline Functional and Symptom Subscales & Strength of Correlation (r-value) & $P$ Value \\
\hline Physical & 0.624 & $<0.05$ \\
Role & 0.521 & $<0.05$ \\
Social & 0.439 & $<0.05$ \\
Cognitive & 0.521 & $<0.05$ \\
Emotional & 0.450 & $<0.05$ \\
Fatigue & -0.604 & $<0.05$ \\
Pain & -0.584 & $<0.05$ \\
Dyspnea & -0.377 & $<0.05$ \\
Insomnia & -0.399 & $<0.05$ \\
Loss of Appetite & -0.442 & $<0.05$ \\
Financial Difficulties & -0.464 & $<0.05$ \\
Heart Burn & -0.369 & $<0.05$ \\
Loss of Hair & -0.262 & $<0.05$ \\
Upset due to loss of hair & -0.452 & $<0.05$ \\
Taste Difference & -0.266 & $<05$ \\
\hline
\end{tabular}

and find appropriate interventions that can improve the quality of life. In this study the physical, psychological, sexual health related factors were evaluated by the EORTC QOL-30 scoring system [16]. We show that that the quality of life is reduced in many domains for ovarian cancer patients receiving chemotherapy. This study focuses on the patients referred to NICRH, the only government cancer hospital in Bangladesh. This population with more than $50 \%$ of patients with a low socioeconomic status has additional stressors related to the challenges to accessing cancer treatment that are common for the poor of Bangladesh [21].

\subsection{QOL Metrics}

Metrics have been established and validated for Quality of Life (QoL) tools by many national and International health organizations. The World Health Organization, with collaboration and input from fifteen public health groups worldwide, developed two instruments to measure QoL, WHOQOL-100 and WHOQOL-BREF [6]. The importance of QoL measurements is the patient-centered nature of the data by documenting the individuals' own perspectives of their well-being. The instruments produce scores related to the various domains of QoL, which includes physical, psychological and social support. The EORTC quality of Life questionnaire was developed to address these important 
issues for cancer patients and was validated for ovarian cancer patients in the 1990's [16] [22]. Since then, this tool has been commonly used as part of assessments of efficacy of therapy, outcomes, and survivorship issues [23]. The direct correlation of QoL with progression free survival in 147 phase III clinical trials was analyzed retrospectively and reported that $67 \%$ of trials reported no effect, $26 \%$ and $7 \%$ reported a positive and negative effective respectively [11]. In contrast, there was a significant difference in overall survival $(\mathrm{p}=0.03)$ between cancer patients whose QoL was assessed through patient-reported outcomes (PRO) for symptom monitoring (median survival 31.2 months) versus usual care (median survival 26 months) [10]. In a systematic review of PRO, 43 publications supported the importance of patient-clinician communication [24]. PRO increased awareness of clinicians to symptoms and problems and allowed further interventions that improved both QoL and survival.

\subsection{Anxiety and Depression}

Anxiety and depression were significant predictors of quality of life. These issues have been reported in other studies as well [25] [26]. In a pilot study of 102 women with ovarian cancer, clinical factors such as stage did not have a significant impact on QoL, rather anxiety, fatigue and cognitive function were the highest priority domains where a reduction in scores was associated with distress [27]. Self-confidence and self-esteem are directly related to QoL in another study of women undergoing treatment for breast cancer [28]. Going through active anticancer therapy such as chemotherapy can trigger depression. In a recent prospective survey of 256 breast cancer patients, $41 \%$ and $26 \%$ respectively reported moderate and severe depression during chemotherapy. This was a doubling of depression prevalence rates compared to this population's experience prior to starting chemotherapy.

\subsection{Fatigue}

Fatigue is associated with a reduction in QoL with worse functioning in all domains for cancer patients [29]. In a study of 109 older patients undergoing chemotherapy, fatigue and financial impact caused the most distress followed by anxiety and depression [30]. In our study, a high proportion of patients suffers from fatigue and was another significant predictor of quality of life.

\subsection{Neuropathy}

Chemotherapy-induced neuropathy is a serious and life-altering consequence of the main chemotherapeutic agents used to treat ovarian cancer including taxanes and platinums [31]. Peripheral neuropathy has a score of 39.76 in this study. It is a major dose limiting side effect and disabling peripheral neuropathy has a significant negative impact on quality of life. Identification of patients with neuropathy may enable the physician to devise prevention strategies prior to the onset of this potentially debilitating complication [32]. Unfortunately, a recent 
systematic review reported that there were no preventative interventions that effectively reduced neuropathies [31]. Supportive measures, such as the use of duloxetine, remain the only effective treatment for painful neuropathies [33]. Physicians will have the weigh the importance of full dose chemotherapy, the indications for chemotherapy (curative versus palliative) with quality of life in the setting of the currently unavoidable neuropathies.

\subsection{Cognitive Challenges}

Both patients and clinicians have described cognitive challenges or "chemo-brain" as an important consequence of chemotherapy [34]. While the etiology of cognitive decline can be multifactorial and can manifest as short-term memory loss and reduced executive functioning, this is associated with patient-reported reduced QoL both during and after cancer treatment.

\subsection{Gastrointestinal Side Effects}

In this study gastrointestinal symptoms such as nausea, vomiting, diarrhea, constipation, and loss of appetite, worsen the quality of life. Chemotherapy-related nausea and vomiting remains a problem in many patients despite the use of $5-\mathrm{HT}_{3}$ receptor antagonists and dexamethasone. Diarrhea and constipation are manifestations of alimentary mucositis, a condition that affects the entire gastrointestinal tract [35] [36].

\subsection{Alopecia}

The women in our study experienced alopecia as the most distressing issue. Factors that contributed to women's distress included: loss of sense of self and altered body image [37]. In a review of 38 articles on chemotherapy and QoL, hair loss was consistently the most troublesome reported side-effect [38]. A prospective study of drawings by fifteen female cancer patients receiving chemotherapy revealed the deep emotional reactions of sadness, insecurity, and disappointment related to alopecia [39].

\subsection{Sexual Dysfunction}

Our patients reported on their experience with poor nutritional status, social insecurity, financial crisis, familial disharmony, and how this affected their psychological wellbeing. Family and partner support have been shown to be important factors in reducing anger about the disease and improved quality of life [40]. In a correlational survey of sexual dysfunction with marital relationship among women with reproductive cancers, $60 \%$ of patients reported a good marital relationship and $19.3 \%$ reported sexual dysfunction. The authors found a significant correlation between the quality of marital relationship and sexual function. Not only are dyspareunia or dryness of the vagina causes of abstinence of sexual activity, but also the fear of harm regarding sexual activity plays important role in sexual dysfunction. In another study, $47 \%$ of ovarian cancer patients were sex- 
ually active. Sexually active patients reported lower levels sexual pleasure and higher levels of sexual discomfort [41]. A survey of sexual health-related issues revealed $54 \%$ of patient were not sexually active and had little or no desire for sexual relation among $74 \%$ of patients [42]. An evaluation of symptoms of ovarian cancer survivors found scores similar to our study with a Global Health Status score of 56.4 but less financial difficulty, more emotional functioning, and better attitudes about the disease [43].

In contrast, in a retrospective study, an average of 24 months after completion of therapy, sexually active ovarian cancer survivors showed no significant difference in sexual function and quality of life compared to healthy non-cancer survivor controls [44]. In another cross-sectional study of ovarian cancer survivors who had completed treatment and were in remission for an average of 56.9 months versus healthy controls, there was no difference in sexual satisfaction exception for vaginal dryness which was greater in those who had undergone cancer treatment [45]. Counseling should be an integral part regarding this issue along with treatment. In addition, support of the family and spouse should be part of a multidisciplinary intervention during cancer treatment.

\subsection{Financial Toxicity}

Financial burdens disproportionately impact patients with cancer of lower social economic status. This is clearly seen in our study of women undergoing chemotherapy at NICRH.

In this study, financial difficulties were associated with worse quality of life. Fifty percent of the study population came from a low socioeconomic background and it was very difficult for them to afford the costs of treatment. Financial instability led to poor treatment adherence, low self-esteem, and ultimately poor QOL. Correlation through multivariate regression has established the negative correlation of the functional and symptomatic subscales on the global health status. Physical, psychological, social, spiritual, and cultural factors should be considered during planning of management and appropriate intervention will help to overcome the barrier to ensure better quality of life in ovarian cancer patients receiving chemotherapy.

In a study of 123 Chinese women with recurrent ovarian cancer, lower financial status was significantly associated with worse QOL on all domains [46]. In a cross-sectional study of ovarian cancer survivors, on average 56 months after treatment, had poorer social functioning and more financial difficulties compared to controls [45].

\section{Strengths and Limitations}

Our study included a large number of women who are currently undergoing chemotherapy for ovarian cancer at single institution. Because the treatment modalities and healthcare providers were similar among all the patients, wide variations in treatments did not occur and the patients' treatment experiences 
were similar. The convenience sampling method allowed the speedy collection of data. On the other hand, convenience sampling may introduce potential bias due to potential under-representation of some subgroups of patients [47]. Additionally, we did not have a control group of healthy women without cancer.

There are few studies and limited research on this topic in developing countries. The aim of this study was to generate a baseline understanding of the topic. Further research is needed to continue to expand knowledge in the area.

\section{Recommendation}

An interdisciplinary team approach to the care of cancer patients is mandatory. Counseling regarding potential impact of chemotherapy and sexual change due to cancer treatment will help to optimize the mental and sexual health. Appropriate interventions to minimize the physical symptoms, psychological impairment and sexual dysfunction will enhance the quality of life. The integration of cancer programs into existing health care services in primary healthcare facilities will also provide the most reliable, cost-effective interventions that can help to overcome money-related hardships.

\section{Conclusion}

Quality of life is composed of broad concepts that affect global life satisfaction. This study addresses the most recent knowledge regarding the impact of the treatment on QOL of ovarian cancer patients in a population of low and middle-income patients in Bangladesh. Provision of supportive care along with effective treatment will ensure better QOL and improve outcomes.

\section{Conflicts of Interest}

The authors declare no conflicts of interest regarding the publication of this paper.

\section{References}

[1] Bray, F., Ferlay, J., Soerjomataram, I., Siegel, R.L., Torre, L.A. and Jemal, A. (2018) Global Cancer Statistics 2018: GLOBOCAN Estimates of Incidence and Mortality Worldwide for 36 Cancers in 185 Countries. CA: A Cancer Journal for Clinicians, 68, 394-424. https://doi.org/10.3322/caac.21492

[2] Howlader, N., Noone, A.M., Krapcho, M., Miller, D., Brest, A., Yu, M., Ruhl, J., Tatalovich, Z., Mariotto, A., Lewis, D.R., Chen, H.S., Feuer, E.J. and Cronin, K.A. (2020) SEER Cancer Statistics Review, 1975-2017. National Cancer Institute, Bethesda, MD. https://seer.cancer.gov/csr/1975 2017/

[3] Coburn, S.B., Bray, F., Sherman, M.E. and Trabert, B. (2017) International Patterns and Trends in Ovarian Cancer Incidence, Overall and by Histologic Subtype. International Journal of Cancer, 140, 2451-2460. https://doi.org/10.1002/ijc.30676

[4] Torre, L.A., Trabert, B., DeSantis, C.E., et al. (2018) Ovarian Cancer Statistics. CA: A Cancer Journal for Clinicians, 68, 284-296. https://doi.org/10.3322/caac.21456

[5] Siegel, R.L., Miller, K.D. and Jemal, A. (2020) Cancer Statistics, 2020. CA: A Cancer Journal for Clinicians, 70, 7-30. https://doi.org/10.3322/caac.21590 
[6] World Health Organization (2020) WHOQOL: Measuring Quality of Life. https://www.who.int/healthinfo/survey/whoqol-qualityoflife/en/

[7] Testa, M.A. and Simonson, D.C. (1996) Assessment of Quality-of-Life Outcomes. The New England Journal of Medicine, 334, 835-840. https://doi.org/10.1056/NEJM199603283341306

[8] Wilson, I.B. and Cleary, P.D. (1995) Linking Clinical variables with Health-Related Quality of Life: A Conceptual Model of Patient Outcomes. JAMA, 273, 59-65. https://doi.org/10.1001/jama.1995.03520250075037

[9] Guyatt, G.H., Feeny, D.H. and Patrick, D.L. (1993) Measuring Health-Related Quality of Life. Annals of Internal Medicine, 118, 622-629. https://doi.org/10.7326/0003-4819-118-8-199304150-00009

[10] Basch, E., Deal, A.M., Dueck, A.C., Scher, H.I., Kris, M.G., Hudis, C. and Schrag, D. (2017) Overall Survival Results of a Trial Assessing Patient-Reported Outcomes for Symptom Monitoring During Routine Cancer Treatment. JAMA, 318, 197-198. https://doi.org/10.1001/jama.2017.7156

[11] Hwang, T.J. and Gyawali, B. (2019) Association between Progression-Free Survival and Patients' Quality of Life in Cancer Clinical Trials. International Journal of Cancer, 144, 1746-1751. https://doi.org/10.1002/ijc.31957

[12] Parmar, M.K.B., Ledermann, J.A., Colombo, N., du Bois, A., Delaloye, J.-F., Kristensen, G.B., Wheeler, S., Swart, A.M., Qian, W., Torri, V., Floriani, I., Jayson, G., Lamont, A., Tropé, C., ICON and AGO Collaborators (2003) Paclitaxel plus Platinum-Based Chemotherapy versus Conventional Platinum-Based Chemotherapy in Women with Relapsed Ovarian Cancer: The ICON 4/AGO-OVAR-2.2 Trial. Lancet, 361, 2099-2106. https://doi.org/10.1016/S0140-6736(03)13718-X

[13] Awadalla, A.W., Ohaeri, J.U., Gholoum, A., Khalid, A.O.A., Hamad, H.M.A. and Jacob, A. (2007) Factors Associated with Quality of Life of Outpatients with Breast Cancer and Gynecologic Cancers and Their Family Caregivers: A Controlled Study. BMC Cancer, 7, Article No. 102. https://doi.org/10.1186/1471-2407-7-102

[14] Sun, C.C., Ramirez, P.T. and Bodurka, D.C. (2007) Quality of Life for Patients with Epithelial Ovarian Cancer. Nature Clinical Practice Oncology, 4, 18-29. https://doi.org/10.1038/ncponc0693

[15] Setia, M.S. (2016) Methodology Series Module 5: Sampling Strategies. Indian Journal of Dermatology, 61, 505-509. https://doi.org/10.4103/0019-5154.190118

[16] Aaronson, N.K., Ahmedzai, S., Bergman, B., Bullinger, M., Cull, A., Duez, N.J., Filiberti, A., Flechtner, H., Fleishman, S.B., de Haes, J.C.J.M., Kaasa, S., Klee, M.C., Osoba, D., Razavi, D., Rofe, P.B., Schraub, S., Sneeuw, K.C.A., Sullivan, M. and Takeda, F. (1993) The European Organisation for Research and Treatment of Cancer QLQ-C30: A Quality-of-Life Instrument for Use in International Clinical Trials in Oncology. Journal of the National Cancer Institute, 85, 365-376.

https://doi.org/10.1093/jnci/85.5.365

[17] Fayers, P.M., Aaronson, N.K., Bjordal, K., Groenvold, M., Curran, D., Bottomley, A. and, on behalf of the EORTC Quality of Life Group (2001) The EORTC QLQ-C30 Scoring Manual. 3rd Edition, European Organization for Research and Treatment of Cancer, Brussels.

[18] PEW Research Center Global Attitudes \& Trends (2014) Emerging and Developing Economies Much More Optimistic than Rich Countries about the Future.

https://www.pewresearch.org/global/2014/10/09/emerging-and-developing-econom ies-much-more-optimistic-than-rich-countries-about-the-future/

[19] McCabe, C., Begley, C., Collier, S. and McCann, S. (2008) Methodological Issues 
Related to Assessing and Measuring Quality of Life in Patients with Cancer: Implications for Patient Care. European Journal of Cancer Care, 17, 56-64. https://doi.org/10.1111/j.1365-2354.2007.00809.x

[20] Heydarnejad, M.S., Hassanpour, D.A. and Solati, D.K. (2011) Factors Affecting Quality of Life in Cancer Patients Undergoing Chemotherapy. African Health Sciences, 11, 266-270.

[21] Pervin, S., Ruma, F.I., Rahman, K., Ferdous, J., Ara, R., Sayed, M.M.A. and Goodman, A. (2019) Adjuvant Hysterectomy in Patients with Residual Disease after Radiation for Locally Advanced Cervical Cancer: A Prospective Longitudinal Study. Journal of Global Oncology, 5, 1-7. https://doi.org/10.1200/JGO.18.00157

[22] Osoba, D., Zee, B., Pater, J., et al. (1994) Psychometric Properties and Responsiveness of the EORTC Quality of Life Questionnaire (QLQ-C30) in Patients with Breast, Ovarian and Lung Cancer. Quality of Life Research, 3, 353-364. https://doi.org/10.1007/BF00451727

[23] Coleridge, S.L., Bryant, A., Lyons, T.J., Goodall, R.J., Kehoe, S. and Morrison, J. (2019) Chemotherapy versus Surgery for Initial Treatment in Advanced Ovarian Epithelial Cancer. Cochrane Database of Systematic Reviews, 2019, Article No. CD005343. https://doi.org/10.1002/14651858.CD005343.pub4

[24] Yang, L.Y., Manhas, D.S., Howard, A.F. and Olson, R.A. (2018) Patient-Reported Outcome Use in Oncology: A Systematic Review of the Impact on Patient-Clinician Communication. Support Care in Cancer, 26, 41-60. https://doi.org/10.1007/s00520-017-3865-7

[25] Holzner, B., Kemmler, G., Meraner, V., et al. (2003) Fatigue in Ovarian Carcinoma Patients: A Neglected Issue? Cancer, 97, 1564-1572.

https://doi.org/10.1002/cncr.11253

[26] Payne, J.K. (2002) The Trajectory of Fatigue in Adult Patients with Breast and Ovarian Cancer Receiving Chemotherapy. Oncology Nursing Forum, 29, 1334-1340. https://doi.org/10.1188/02.ONF.1334-1340

[27] Teng, F.F., Kalloger, S.E., Brotto, L. and McAlpine, J.N. (2014) Determinants of Quality of Life in Ovarian Cancer Survivors: A Pilot Study. Journal of Obstetrics and Gynaecology Canada, 36, 708-715. https://doi.org/10.1016/S1701-2163(15)30513-2

[28] Sehati Shafaee, F., Mirghafourvand, M., Harischi, S., Esfahani, A. and Amirzehni, J. (2018) Self-Confidence and Quality of Life in Women Undergoing Treatment for Breast Cancer. Asian Pacific Journal of Cancer Prevention, 19, 733-740. https://dx.doi.org/10.22034/APJCP.2018.19.3.733

[29] Annunziata, M.A., Muzzatti, B., Mella, S. and Bidoli, E. (2013) Fatigue, Quality of Life, and Mood States during Chemotherapy in Italian Cancer Patients. Tumori Journal, 99, e28-e33. https://doi.org/10.1177/030089161309900129

[30] Li, Q., Lin, Y., Qiu, Y., Gao, B. and Xu, Y. (2014) The Assessment of Health-Related Quality of Life and Related Factors in Chinese Elderly Patients Undergoing Chemotherapy for Advanced Cancer: A Cross-Sectional Study. European Journal of Oncology Nursing, 18, 425-435. https://doi.org/10.1016/j.ejon.2014.03.005

[31] Loprinzi, C.L., Lachetti, C., Bleeker, J., Cavaletti, G., Chauhan, C., Hertz, D.L., Kelley, M.R., Lavino, A., Lustberg, M.B., Paice, J.A., Schneider, B.P., Lavoie Smith, E.M., Smith, M.L., Smith, T.J., Wagner-Johnston, N. and Hershman, D.L. (2020) Prevention and Management of Chemotherapy-Induced Peripheral Neuropathy in Survivors of Adult Cancers: ASCO Guideline Update. Journal of Clinical Oncology, 38, 3325-2248. https://doi.org/10.1200/JCO.20.01399 
[32] Ocean, A.J. and Vahdat, L.T. (2004) Chemotherapy-Induced Peripheral Neuropathy: Pathogenesis and Emerging Therapies. Supportive Care in Cancer, 12, 619-625. https://doi.org/10.1007/s00520-004-0657-7

[33] Salehifar, E., Janbabaei, G., Hendouei, N., Alipour, A., Tabrizi, N. and Avan, R. (2020) Comparison of the Efficacy and Safety of Pregabalin and Duloxetine in Taxane-Induced Sensory Neuropathy: A Randomized Controlled Trial. Clinical Drug Investigation, 40, 249-257. https://doi.org/10.1007/s40261-019-00882-6

[34] Tschernicovsky, R., Philp, L. and Goodman, A. (2019) Chemotherapy-Induced Cognitive Decline Moving from the Mechanistic Debate towards Prevention and Treatment-A Clinical Review. Journal of Cancer Therapy, 10, 985-1012. https://doi.org/10.4236/jct.2019.1012084

[35] Warr, D.G. (2008) Chemotherapy and Cancer Related Nausea and Vomiting. Currrent Oncology, 15, S4-S9. https://doi.org/10.3747/c0.2008.171

[36] Gibson, R.J. and Keefe, D.M.K. (2006) Cancer Chemotherapy-Induced Diarrhoea and Constipation: Mechanisms of Damage and Prevention Strategies. Supportive Care in Cancer, 14, Article No. 890. https://doi.org/10.1007/s00520-006-0040-y

[37] Jayde, V., Boughton, M. and Blomfield, P. (2013) The Experience of Chemotherapy-Induced Alopecia for Australian Women with Ovarian Cancer. European Journal of Cancer Care, 22, 503-512. https://doi.org/10.1111/ecc.12056

[38] Lemieux, J., Maunsell, E. and Provencher, L. (2008) Chemotherapy-Induced Alopecia and Effects on Quality of Life among Women with Breast Cancer: A Literature Review. Psycho-Oncology, 17, 317-328. https://doi.org/10.1002/pon.1245

[39] van Alphen, K., Versluis, A., Dercksen, W., de Haas, H., Lugtenberg, R., Tiemensma, J., Kroep, J., Broadbent, E., Kaptein, A.A. and van den Hurk, C. (2020) Giving a Face to Chemotherapy-Induced Alopecia: A Feasibility Study on Drawings by Patients. Asia-Pacific Journal of Oncology Nursing, 7, 218-224. https://doi.org/10.4103/apjon.apjon 820

[40] Julkunen, J., Gustavsson-Lilius, M. and Hietanen, P. (2009) Anger Expression, Partner Support, and Quality of Life in Cancer Patients. Journal of Psychosomatic Research, 66, 235-244. https://doi.org/10.1016/j.jpsychores.2008.09.011

[41] Liavaag, A.H., Dørum, A., Bjøro, T., et al. (2008) A Controlled Study of Sexual Activity and Functioning in Epithelial Ovarian Cancer Survivors. A Therapeutic Approach. Gynecologic Oncology, 108, 348-354. https://doi.org/10.1016/j.ygyno.2007.10.009

[42] Thranov, I. and Klee, M. (1994) Sexuality among Gynecologic Cancer Patients-A Cross-Sectional Study. Gynecologic Oncology, 52, 14-19.

https://doi.org/10.1006/gyno.1994.1004

[43] Meraner, V., Gamper, E.-M. and Grahmann, A., et al. (2012) Monitoring Physical and Psychosocial Symptom Trajectories in Ovarian Cancer Patients Receiving Chemotherapy. BMC Cancer, 12, Article No. 77.

https://doi.org/10.1186/1471-2407-12-77

[44] Mayer, S., Iborra, S., Grimm, D., Steinsiek, L., Mahner, S., Bossart, M., Woelber, L. Voss, P.J., Gitsch, G. and Hasenburg, A. (2019) Sexual Activity and Quality of Life in Patients after Treatment for Breast and Ovarian Cancer. Archives of Gynecology and Obstetrics, 299, 191-201. https://doi.org/10.1007/s00404-018-4922-2

[45] Kim, S.I., Lee, Y., Lim, M.C., Joo, J., Park, K., Lee, D.O. and Park, S.Y. (2015) Quality of Life and Sexuality Comparison between Sexually Active Ovarian Cancer Survivors and Healthy Women. Journal of Gynecologic Oncology, 26, 148-154. https://doi.org/10.3802/jgo.2015.26.2.148 
[46] Shao, Z.Y., Zhu, T., Zhang, P., Wen, Q., Li, D. and Wang, S.H. (2017) Association of Financial Status and the Quality of Life in Chinese Women with Recurrent Ovarian Cancer. Health and Quality of Life Outcomes, 15, Article No. 144. https://doi.org/10.1186/s12955-017-0714-9

[47] Bornstein, M.H., Jager, J. and Putnick, D.L. (2017) Sampling in Developmental Science: Situations, Shortcomings, Solutions, and Standards. Developmental Review, 33, 357-370. https://doi.org/10.1016/j.dr.2013.08.003 